\title{
WORKSHOP DAN PENDAMPINGAN PENGGUNAAN E-GOVERNMENT BERUPA SISKEUDES KEPADA APARATUR DESA DI KABUPATEN KARAWANG
}

\author{
Aulia Fashanah Hadining1), Cindi Ramayanti'2), Madjidainun Rahma ${ }^{3)}$ \\ 1)Teknik Industri, Fakultas Teknik, Universitas Singaperbangsa Karawang, Karawang, Jawa Barat, Indonesia \\ 2)Teknik Kimia, Politeknik Negeri Palembang, Palembang, Sumatera Selatan, Indonesia \\ ${ }^{3)}$ Akuntansi, Fakultas Ekonomi dan Bisnis, Universitas Singaperbangsa Karawang, Karawang, Jawa Barat, Indonesia \\ Corresponding author: Aulia Fashanah Hadining \\ E-mail : aulia.fasha@ft.unsika.ac.id
}

Diterima 30 April 2021, Direvisi 24 Mei 2021, Disetujui 25 Mei 2021

\begin{abstract}
ABSTRAK
Penggunaan aplikasi Siskedeus saat ini menjadi perhatian penting dari pemerintah. Siskedeus membantu agar segala proses pengelolaan keuangan desa transparan dan akuntabel. Wajibnya penggunaan aplikasi Siskedeus ini, membuat para aparatur desa perlu untuk memahami dan menguasai penggunaan perangkat lunak komputer serta dasar akuntansi agar dapat terciptanya efisiensi dan efektivitas dalam penggunaan aplikasi Siskedeus. Kegiatan pengabdian kepada masyarakat ini bermitra dengan Dinas Pemberdayaan Masyarakat dan Desa Kabupaten Karawang dimana peserta dari kegiatan ini adalah para admin aplikasi Siskedeus yang berjumlah 297 orang. Kegiatan workshop yang dilakukan menggunakan metode ceramah dan praktek langsung secara simulasi yang berbasis digital dengan menggunakan aplikasi Zoom Meeting. Materi yang disampaikan terdiri dari pemahaman tentang dasar-dasar komputer beserta penggunaan aplikasi Microsoft Excel, dan dasar-dasar akuntasi serta laporan keuangan. Setelah selesai dilakukan pelatihan, peserta diberikan pertanyaan-pertanyaan evaluasi pelatihan sebagai bahan penilaian dari pelaksanaan pelatihan. Hasil penilaian pada tahap evaluasi didapat bahwa sebesar $57,4 \%$ dan $59,3 \%$ dari total peserta merasa kegiatan ini sesuai dengan tujuan kegiatan pengabdian kepada masyarakat yaitu meningkatkan pemahaman para aparatur desa dalam menggunakan Siskeudes dan memberikan manfaat terhadap pelaksanaan pekerjaan menggunakan aplikasi Siskedeus masing-masing sebesar jawaban dari total peserta. Sebesar $54,9 \%$ dan $57,8 \%$ dari total peserta juga berpendapat bahwa para pemateri dapat menyampaikan materi dengan jelas dan mudah dipahami serta memberikan respon yang baik kepada peserta.
\end{abstract}

Kata kunci: aplikasi; e-government; siskeudes.

\begin{abstract}
The use of the Siskedeus application is currently an important concern of the government. Siskedeus helps make all village financial management processes transparent and accountable. The mandatory use of the Siskedeus application makes village officials need to understand the use of computer software and the basis of accounting in order to create efficiency and effectiveness in using the Siskedeus application. The activities carried out here are in partnership with the Community and Village Empowerment Service of Karawang Regency where the participants of this activity are 297 administrators of the Siskedeus application. Workshop activities are carried out using the lecture method and direct practice in a digital-based simulation using the Zoom Meeting application. The material presented consists of an understanding of basic computers along with the use of the Microsoft Excel application, and basic accounting and financial report. After completing the training, participants are given training evaluation questions as an assessment material for training implementation. The results of the evaluation showed that $57.4 \%$ and $59.3 \%$ of the total participants felt that this activity was in accordance with the objectives of community service activities to increase knowledge of the user about siskeudes usage and provided benefits for the implementation of work using the Siskedeus application, respectively for the answers of the total participants. $54.9 \%$ and $57.8 \%$ of the total participants also thought that the presenters could convey the material clearly and easily understood and gave good responses to the participants.
\end{abstract}

Keywords: application; e-government; siskeudes. 


\section{PENDAHULUAN}

Perkembangan teknologi memberikan perubahan yang cukup siginifikan pada proses bisnis organisasi. Tavana et al (Tavana et al., 2013) mengungkapkan bahwa perkembangan teknologi informasi dan komunikasi telah merubah proses dan perilaku bisnis termasuk diantaranya adalah proses bisnis pemerintah. Hal ini terjadi karena teknologi informasi dan komunikasi memberikan berbagai macam kemudahan dalam proses bisnis. Manfaat tersebut antara lain adalah penghematan biaya (Sharma \& Mishra, 2017; Tavana et al., 2013) dan proses pelaporan yang lebih cepat dan transparan (Susanto et al., 2017). Oleh karena itu dapat disimpulkan bahwa teknologi komunikasi dapat membantu pemerintah untuk bekerja lebih efektif dan efisien. Teknologi informasi tersebut biasa dikenal sebagai $E$ government. Salah satu kegiatan yang membutuhkan pengawasan ketat adalah kegiatan pengelolaan keuangan desa. Berdasarkan Undang-Undang Nomor 6 Tahun 2014 dan Permendagri No. 113 Tahun 2014, Desa memiliki kewajiban untuk mengelola dana desa yang berjumlah 800 juta hingga 1 miliar secara transparan, akuntabel, partisipatif, tertib dan disiplin anggaran (Nintyari et al., 2019). Oleh karena itu, Pemerintah mewajibkan desa untuk menggunakan aplikasi Sistem Keuangan Desa untuk mendukung pekerjaan pengelolaan keuangan desa agar dapat tercipta transparansi dan akuntabilitas keuangan desa (Riani et al., 2019). Bima et al (Bima et al., 2020) mengungkapkan bahwa keuangan desa yang bersumber dari Dana Desa harus dikelola dengan baik untuk dapat digunakan dalam kegiatan peningkatan kesejahteraan masyarakat desa. Pemerintah memanfaat aplikasi Sistem Keuangan Desa (Siskeudes) untuk membantu para aparatur desa dalam mengelola Dana Desa sehingga terwujud transparansi dalam pelaporan keuangan desa. Berdasarkan data BPKP, penggunaan aplikasi Siskeudes telah mencapai lebih dari $90 \%$ pada tahun 2019 (BPKP, 2020). Mitra dalam kegiatan Pengabdian kepada Masyarakat (PKM) adalah Dinas Pemberdayaan Masyarakat dan Desa Kabupaten Karawang. Secara khusus, kerjasama dilakukan dengan Pak Nunu Nugraha yaitu koordinator admin E-government 2020 berupa Siskeudes di Kabupaten Karawang. Pak Nunu membawahi keseluruhan admin Siskeudes yang berada di 297 desa di Kabupaten Karawang. E-government yang menjadi fokus kajian pada Pengabdian kepada Masyarakat ini adalah aplikasi Siskeudes. Berdasarkan studi pendahuluan yang dilakukan dengan terjun langsung ke desa dan melakukan wawancara dengan para perangkat desa, diperoleh hasil bahwa seluruh desa di Kabupaten Karawang telah menggunakan aplikasi Siskeudes untuk membuat pelaporan laporan keuangan desa. Namun, masih ditemukan keluhan yaitu sulitnya penggunaan aplikasi karena berbagai hal seperti pemahaman terkait sistem operasi aplikasi, pemahaman terkait akuntasi yang digunakan dalam laporan keuangan desa, dan kurangnya motivasi aparatur desa dalam menggunakan aplikasi Siskeudes. Menurut Nintyari et al. (Nintyari et al., 2019) kompetensi yang dimiliki oleh sumber daya manusia desa berpengaruh terhadap efektivitas dan efisiensi penggunaan Siskeudes. Selain itu, sosialisasi dan manajemen kontrol terhadap penggunaan Siskeudes juga dapat mendorong efektivitas dan efisiensi menjadi lebih baik (Malahika et al., 2018). Hal ini dapat terwujud dengan memberikan sosialisasi dan pelatihan dasar untuk menggunakan aplikasi Siskeudes. Oleh karena itu, dapat disimpulkan bahwa sosialisasi dan pelatihan sangat dibutuhkan untuk dapat meningkatan sumber daya manusia dalam menggunakan aplikasi Siskeudes agar lebih efektif dan efisien.

Workshop dan Pendampingan penggunaan e-government di Kabupaten Karawang fokus kepada peningkatan pemahaman bagi aparatur desa. Kegiatan ini bertujuan untuk dapat meningkatkan pemahaman penggunaan aplikasi Siskeudes bagi sumber daya manusia dan aparatur desa di Kabupaten Karawang.

\section{METODE}

Kegiatan pengabdian kepada masyarakat ini merupakan salah satu bagian dari tridharma perguruan tinggi. Kegiatan Pengabdian kepada masyarakat yang dilaksanakan berupa workshop dan pendampingan penggunaan e-government dalam hal ini adalah aplikasi Siskeudes. Mitra dari pengabdian ini adalah seluruh admin aplikasi Siskeudes di 297 desa di Kabupaten Karawang yang berada dalam naungan Dinas Pemberdayaan Masyarakat dan Desa Kabupaten Karawang. Pelatihan dilaksanakan pada hari Selasa, 3 November 2020 dengan memanfaatkan aplikasi Zoom Meeting.

$$
\text { Kegiatan Pengabdian kepada }
$$

Masyarakat ini berupa pelatihan dasar komputer dan akuntansi untuk mempermudah penggunaan e-government. Hal ini sejalan dengan judul pengabdian kepada masyarakat yaitu workshop dan pendampingan penggunaan e-government di kabupaten karawang. Penerapan workshop ini berbasis digital dengan memanfaatkan aplikasi Zoom Meeting. Hal ini dilakukan karena kondisi 
pandemi Covid-19 yang tidak memungkinkan untuk melakukan kegiatan workshop.

Metode yang diaplikasikan dalam workshop ini adalah metode ceramah dan praktek langsung secara simulasi, sebagaimana yang dilakukan oleh (Dewi \& Handayani, 2020) dalam kegiatan pengabdian kepada masyarakat pada masa pandemi. Metode ceramah dilakukan karena dinilai efektif untuk menjelaskan materi terutama pada proses pembelajaran dan pelatihan jarak jauh pada masa pandemi Covid-19 (Suhardin, 2020) . Pada metode ceramah termasuk di dalamnya adalah penjelasan dan diskusi serta tanya jawab. Ceramah dan simulasi dilakukan untuk dua materi berbeda yang bermanfaat untuk menjadi dasar penggunaan aplikasi Siskeudes. Materi pertama adalah materi tentang dasar penggunaan komputer yang berisi segala hal tentang hardware dan software komputer, penanganan malware, perawatan file hingga perawatan komputer secara keseluruhan. Selain itu pada materi dasar komputer juga dipaparkan tentang dasar penggunakan aplikasi Microsoft Excel yang dapat bermanfaat untuk pembuatan jurnal akuntansi. Materi kedua adalah materi tentang akuntansi dasar yang di dalamnya berisi pengetahuan tentang proses dalam penjurnalan akuntansi, jenis-jenis akun dalam laporan keuangan desa, jenis-jenis laporan keuangan desa, serta penerapan akuntansi dalam aplikasi Siskeudes. Simulasi dilakukan setelah penyampaian ceramah tentang materi dasar. Pada materi 1, simulasi b diperlihatkan tentang penggunaan rumus dasar akuntansi dalam aplikasi Microsot Excel. Pada materi 2, simulasi diperlihatkan tentang penerapan teoriteori akuntansi pada aplikasi Siskeudes. Alur kegiatan dan metode ditunjukkan pada Gambar 1.

\section{HASIL DAN PEMBAHASAN}

Pelatihan dilaksanakan dalam bentuk webinar yang dihadiri oleh seluruh admin Siskeudes di Kabupaten Karawang. Pelatihan dilaksanakan secara online dengan aplikasi Zoom Meeting dengan beberapa pertimbangan, antara lain yaitu kondisi wabah pandemi Covid19 yang masih terus meningkat jumlah korbannya, jarak antara desa yang satu dengan desa yang lain cukup jauh sehingga membutuhkan sarana transportasi yang cukup mahal, serta banyaknya jumlah admin Siskeudes.

Pelatihan dilaksanakan dalam waktu 1 hari selama 6 jam dimulai dari jam 08.00 hingga jam 09.00 pagi untuk registrasi peserta pelatihan dan pembukaan oleh ketua panitia pengabdian kepada masyarakat dan perwakilan Dinas Pemberdayaan Masyarakat dan Desa Kabupaten Karawang. Acara dilanjutkan dengan materi pertama yaitu dasar komputer dan dasar microsoft excel dimulai pukul 09.00 hingga pukul 11.30 yang didalamnya terdapat ceramah, simulasi, serta sesi tanya jawab dan diskusi. Kemudian acara dilanjutkan dengan materi kedua yaitu materi dasar akuntansi dan laporan keuangan yang didalamnya terdapat ceramah, simulasi input aplikasi Siskeudes, dan diskusi yang dimulai pukul 11.30 hingga 14.00. Terakhir acara penutupan dengan foto bersama dan mengisi link absensi yang berisi evaluasi pelatihan. Peserta pelatihan memperoleh souvenir pelatihan dan sertifikat sebagai penghargaan telah mengikuti pelatihan.

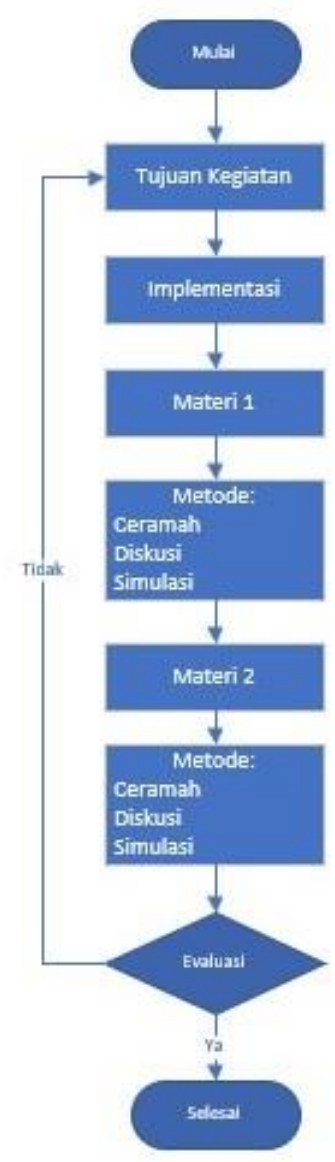

Gambar 1. Alur kegiatan dan metode pelaksanaan kegiatan (Sumber: Penulis, 2021)

Pelatihan dalam kegiatan Pengabdian kepada Masyarakat ini dilaksanakan secara online melalui aplikasi Zoom Meeting. Dokumentasi dari pemaparan materi pada pelatihan yang dilaksanakan tampak pada Gambar 2. 


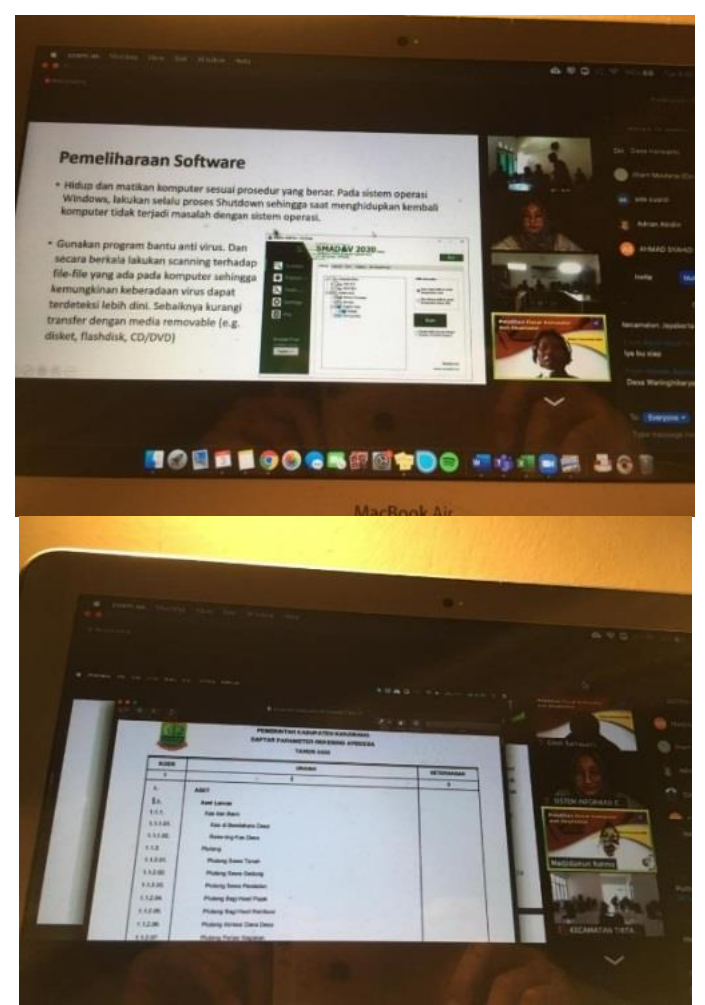

Gambar 2. Pemaparan Materi Pelatihan Penggunaan E-government. Atas: Materi Dasar komputer dan dasar microsoft excel. Bawah: Materi dasar akuntansi (Sumber: Penulis, 2021)

Gambar 2 adalah dokumentasi pemaparan materi yang disampaikan pada pelatihan. Dokumentasi pada saat melakukan sesi foto bersama tampak pada Gambar 3.

Setelah melakukan sesi foto bersama kemudian acara dilanjutkan dengan pengisian link absensi yang berisi pertanyaan mengenai data diri peserta dan evaluasi pelatihan. Evaluasi pelatihan digunakan untuk dapat mengetahui pendapat peserta terhadap pelatihan yang diperoleh sehingga dapat menjadi penilaian terhadap pelatihan. Penilaian tersebut digunakan untuk peningkatan kualitas pelatihan dikemudian hari. Terdapat empat pertanyaan mengenai evaluasi pelatihan yang dijawab berdasarkan skala Likert dengan rentang 1 hingga 5. Rentang penilaian tersebut yaitu 1 untuk sangat tidak setuju (STS), 2 untuk tidak setuju (TS), 3 untuk cukup setuju (N), 4 untuk setuju (S), dan 5 untuk sangat setuju (SS). Terdapat empat pertanyaan yang berkaitan dengan evaluasi pelatihan. Pertanyaan pertama berisi tentang kesesuaian dengan pelatihan dengan tujuan yang ingin dicapai (EVAL 1), manfaat pelatihan bagi pekerjaan (EVAL 2), kejelasan penyampaian materi dan kemudahan materi untuk dapat dipahami (EVAL 3), dan respon pemateri dengan pertanyaan peserta (EVAL 4). Dari 297 admin Siskeudes yang diundang, terdapat 204 data evaluasi yang dapat diolah. Pengolahan data memanfaat aplikasi Microsoft Excel yang tampak pada Gambar 4

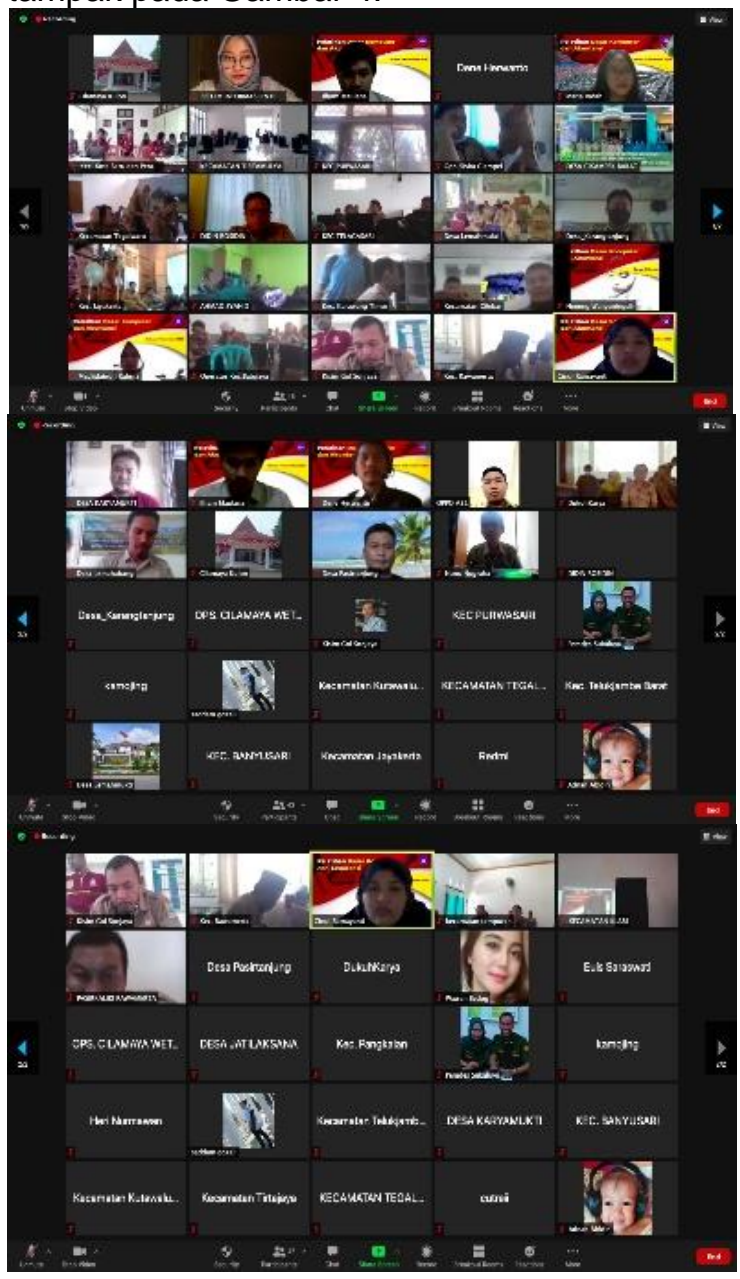

Gambar 3. Sesi foto peserta pada saat pelatihan

(Sumber: Penulis, 2021)

Tabel 1. Hasil Evaluasi Terhadap Pelatihan

\begin{tabular}{lcccc}
\hline & \multicolumn{4}{c}{ JUMLAH } \\
\cline { 2 - 5 } SKALA & $\begin{array}{c}\text { EVAL 1 } \\
\text { (peserta } \\
\text { ) }\end{array}$ & $\begin{array}{c}\text { EVAL 2 } \\
\text { (peserta } \\
\text { ) }\end{array}$ & $\begin{array}{c}\text { EVAL 3 } \\
\text { (peserta } \\
\text { ) }\end{array}$ & $\begin{array}{c}\text { EVAL 4 } \\
\text { (peserta } \\
\text { ) }\end{array}$ \\
\hline STS & 2 & 2 & 2 & 2 \\
TS & 2 & 3 & 3 & 2 \\
N & 40 & 31 & 51 & 45 \\
S & 117 & 121 & 112 & 118 \\
SS & 43 & 47 & 36 & 37 \\
TOTAL & $\mathbf{2 0 4}$ & $\mathbf{2 0 4}$ & $\mathbf{2 0 4}$ & $\mathbf{2 0 4}$ \\
Prosentas & & & 54,9 & 57,8 \\
e & 57,4 & 59,3 & 54
\end{tabular}

(Sumber: Penulis, 2021)

Tabel 4 menunjukkan hasil evaluasi terhadap pelatihan. Dari hasil pengolahan data evaluasi tampak bahwa 117 peserta, atau sebanyak $57,4 \%$ dari total peserta, merasa setuju bahwa pelatihan sesuai dengan tujuan kegiatan pengabdian kepada masyarakat. Sebanyak 121 peserta, atau sebanyak 59,3\% 
dari total peserta, merasa setuju bahwa pelatihan ini dapat memberi manfaat bagi pelaksaan pekerjaan mereka terkait dengan aplikasi Siskeudes. Sebanyak 112 peserta, atau sebanyak 54,9\% dari total peserta, merasa setuju bahwa materi yang disampaikan jelas dan mudah dipahami. Sebanyak 118 peserta, atau $57,8 \%$ dari total peserta, merasa setuju bahwa pemateri memberikan respon yang baik terhadap pertanyaan yang disampaikan peserta pada saat pelatihan. Dari keseluruhan hasil pengolahan data, dapat disimpulkan bahwa pelatihan sudah dilaksanakan dengan cukup baik.

\section{SIMPULAN DAN SARAN}

Kegiatan pelaksanaan Pengabdian Kepada Masyarakat ini telah dilaksanakan dengan baik. Pelatihan ini dilakukan dengan tujuan untuk meningkatkan pemahaman kepada para aparatur desa terutama para admin Siskedeus di Kabupaten Karawang tentang penggunaan aplikasi Siskedeus. Berdasarkan hasil dari evaluasi yang diberikan setelah kegiatan dilakukan, dapat diberikan kesimpulan bahwa pelatihan ini sesuai dengan tujuan kegiatan pengabdian kepada masyarakat dan memberikan manfaat bagi para admin Siskedeus dalam meningkatkan pemahaman mereka terhadap penggunaan aplikasi Siskedeus guna membantu dan mempermudah pelaksanaan pekerjaan mereka. Para peserta pelatihan juga setuju bahwa pemateri menyampaikan materi dan memberikan respon dengan baik dan jelas sehingga para peserta mudah dalam memahami materi yang disampaikan. Walaupun kegiatan pelaksanaan ini dilakukan di tengah pandemi Covid-19, akan tetapi berkat bantuan dari mitra yaitu Dinas Pemberdayaan Masyarakat dan Desa Kabupaten Karawang yang telah berperan sebagai fasilitator kegiatan ini sehingga pelatihan dapat berjalan dengan baik dan sesuai dengan rencana dan tujuan yang diharapkan.

Saran yang dapat dilakukan sebagai bentuk tindak lanjut dari kegiatan ini adalah berupa pengawasan dalam penggunaan aplikasi Siskeudessehingga dapat dilakukan evaluasi dalam penggunaan aplikasi. Selain itu juga dibutuhkan pelatihan terkait disiplin ilmu lainnya yang dapat digunakan untuk mempermudah dalam penggunaan aplikasi Siskeudes.

\section{UCAPAN TERIMAKASIH}

Ucapan terima kasih kepada Universitas Singaperbangsa Karawang melalui Lembaga Penelitian dan Pengabdian Kepada Masyarakat (LPPM) yang telah memberikan dana dalam skema Hibah Penelitian Pemula (HIPLA) sehingga kegiatan ini dapat berjalan dengan baik.

\section{DAFTAR RUJUKAN}

Bima, M. R., Kamal, M., \& Djanggih, H. (2020). Pelatihan Dan Penyuluhan Pengelolaan Alokasi Dana Desa (Add). Jurnal Inovasi Hasil Pengabdian Masyarakat (Jipemas), 3(1), 63-77. Https://Doi.Org/Http://Dx.Doi.Org/10.33 474/Jipemas.V3i1.5011

Bpkp. (2020). Pengawalan Keuangan Desa Dengan Aplikasi Siskeudes. Http://Www.Bpkp.Go.Id/Sakd/Konten/2 448/Leaflet-Simda-Desa.Bpkp

Dewi, T. U., \& Handayani, S. L. (2020). Pelatihan Pembuatan Soal Berbasis Digital Bagi Guru Sma Di Era Revolusi Industri 4.0. Jurnal Inovasi Hasil Pengabdian Masyarakat (Jipemas. Jurnal Inovasi Hasil Pengabdian Masyarakat (Jipemas), 3(2), 146-153. Https://Doi.Org/Http://Dx.Doi.Org/10.33 474/Jipemas.V3i2.6697

Malahika, J. M., Karamoy, H., \& Pusung, R. J. (2018). Penerapan Sistem Keuangan Desa (Siskeudes) Pada Organisasi Pemerintahan Desa (Studi Kasus Di Desa Suwaan Kecamatan Kalawat Kabupaten Minahasa Utara). Going Concern : Jurnal Riset Akuntansi, 13(4), 578-583.

Https://Doi.Org/Https://Doi.Org/10.324 00/Gc.13.04.21514.2018

Nintyari, L. Restiti, Kurniawan, P. S., \& Anantawikrama Tungga, A. (2019). Pengaruh Kompetensi Sumber Daya Manusia, Sosialisasi, Serta Manajemen Kontrol Terhadap Efektivitas Dan Efisiensi Pelaksanaan Sistem Keuangan Desa (Siskeudes) (Studi Empiris Pada Desa-Desa Penerima Dana Desa Di Kabupaten Tabanan). Jimat (Jurnal IImiah Mahasiswa Akuntansi) Universitas Pendidikan Ganesha, 10(2). Https://Doi.Org/Http://Dx.Doi.Org/10.23 887/Jimat.V10i2.20512

Riani, F., Kalalinggi, R., \& Anggraeiny, R. (2019). Implementasi Aplikasi Sistem Keuangan Desa (Siskeudes) Pada Pemerintahan Desa Karya Bhakti Kecamatan Muara Wahau Kabupaten Kutai Timur. Ejournal Pemerintahan Integratif, 7(4), 448-457.

Sharma, R., \& Mishra, R. (2017). Investigating The Role Of Intermediaries In Adoption Of Public Access Outlets For Delivery Of E-Government Services In 
Developing Countries: An Empirical Study. Government Information Quarterly, 34(4), 658-679. Https://Doi.Org/10.1016/J.Giq.2017.10. 001

Suhardin, S. (2020). Penguatan Kemampuan Guru Menggunakan Lecture Strategy Dalam Pembelajaran Jarak Jauh (Pjj) Di Tengah Pandemi Covid-19. Jurnal Syntax Transformation, 1(7), 387-396.

Susanto, T. D., Diani, M. M., \& Hafidz, I. (2017). User Acceptance Of E-Government Citizen Report System (A Case Study Of City113 App). Procedia Computer Science, 124, 560-568. Https://Doi.Org/Https://Doi.Org/10.101 6/J.Procs.2017.12.190

Tavana, M., Zandi, F., \& Katehakis, M. N. (2013). A Hybrid Fuzzy Group AnpTopsis Framework For Assessment Of E-Government Readiness From A Cirm Perspective. Information \& Management, 50(7), 383-397. Https://Doi.Org/Https://Doi.Org/10.101 6/J.Im.2013.05.008 